\title{
La conversión religiosa como instrumento de búsqueda y construcción de identidades: el budismo tibetano en España
}

\author{
Religious conversion as an instrument of search and building \\ identities: Tibetan Buddhism in Spain
}

\author{
Carmen Castilla-Vázquez \\ Universidad de Granada (España) \\ mccv@ugr.es \\ Fecha de recepción: 30/12/2018 \\ Fecha de aceptación: 19/06/2019
}

\begin{abstract}
Resumen
Aunque el mapa religioso de la España actual ha cambiado considerablemente como consecuencia de la inmigración, no es solamente este factor el único a tener en cuenta a la hora de mencionar el cambio que ha experimentado la sociedad española en materia religiosa pues, el número de españoles que se convierten desde el catolicismo a otras confesiones ha aumentado extraordinariamente. Este trabajo busca reflexionar sobre los procesos de conversión al budismo en España, tomando como ejemplo, la ciudad de Granada, a partir de observaciones etnográficas y través del relato biográfico que nos ofrecen personas conversas a esta religión. Además de analizar los motivos que les llevaron a la conversión, nos acercamos a la manera en que estas personas han construido su nueva identidad religiosa, modificando su sistema de creencias y valores, así como su percepción de la sociedad en la que viven.
\end{abstract}

Palabras clave: Conversión; Budismo; Identidad religiosa; Espiritualidad; Andalucía.

\begin{abstract}
Although the religious map of Spain today has changed considerably as a result of immigration, this is not the only factor to take into consideration when mentioning the change in religious matters that the Spanish society has experienced. The number of Spaniards that convert from Catholicism to other faiths has increased remarkably as well. This project seeks to reflect on the processes of conversion to Buddhism in Spain, using the city of Granada as an example. This analysis is based on ethnographic observations and the biographical testimony offered by people who converted to Buddhism. In addition to analyzing the reasons that led to this
\end{abstract}


La conversión religiosa como instrumento de búsqueda... - C. Castilla-Vázquez

conversion, we also shed light on the way in which these individuals have built their new religious identity, modifying their system of beliefs and values as well as their perception of the society they live in.

Keywords: Conversión; Buddhism; Religious identity; Spirituality; Andalusia.

\section{INTRODUGCIÓN}

El catolicismo sigue siendo la confesión más numerosa en España como ponen de manifiesto los datos del Centro de Investigaciones Sociológicas, de enero de 2017 donde un $69,8 \%$ de la población española se considera católica'. Sin embargo, esta misma población se declara poco practicante, habiendo disminuido su porcentaje en más de 20 puntos en las últimas cuatro décadas. Por otro lado, España en poco más de diez años se ha convertido en un país receptor de un importante flujo de población extranjera lo que ha venido a debilitar la supuesta homogeneidad cultural y religiosa con la proliferación de una gran cantidad de nuevas culturas cuando no de nuevas confesiones religiosas. Sin embargo, no podemos decir que todas las confesiones no católicas que actualmente están implantadas en España sean nuevas. Pues la presencia de muchas de ellas se remonta muy atrás. Lo que si podemos afirmar es que gracias a la Ley Orgánica de Libertad Religiosa de 1980 algunas de estas confesiones han experimentado un crecimiento considerable y, sobre todo, se han hecho visibles. De esta forma, evangélicos, testigos de Jehová o mormones, han recuperado una visibilidad y una memoria muchas veces oculta por el temor a ser estigmatizados.

No obstante, aunque el mapa religioso de la España actual ha cambiado considerablemente como consecuencia de la inmigración, no es solamente este factor el único a tener en cuenta a la hora de mencionar el cambio que ha experimentado la sociedad española en materia religiosa pues, el número de españoles que se convierten desde el catolicismo a otras confesiones ha aumentado extraordinariamente.

Este artículo, enmarcado dentro de un proyecto más amplio que trata de estudiar los procesos de conversión religiosa en España desde los presupuestos teóricos de la Antropología de la religión, se ha centrado en esta ocasión en el budismo, una religión que ha ido ganando adeptos en los últimos años, hasta el punto de conseguir la condición de notorio arraigo en el año 2007 (Fernández-Coronado, 2009, pp. 137154). Para ejemplificar el trabajo nos hemos acercado al centro Nagarjuna, en la ciudad de $\mathrm{Granada}^{2}$, un espacio dedicado a impartir estudios de budismo tibetano.

1 Centro de Investigaciones Sociológicas (1 de febrero de 2017). Barómetro de febrero de 2017. p. 25. Disponible en: http://www.cis.es/cis/opencm/ES/1_encuestas/estudios/ver.jsp?estudio=14329

2 La provincia de Granada (España) cuenta con unos seis centros y retiros budistas. El crecimiento e interés por el budismo en esta provincia, refleja los motivos espirituales de una población española que no ha tenido contacto con culturas de larga tradición budista. 


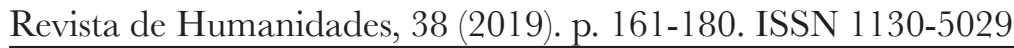

Desde ahí, hemos podido contactar con personas interesadas y conversas a esta religión.

Entre los objetivos que perseguimos está en primer lugar, interesarnos por los motivos que llevaron al sujeto a la búsqueda de nuevas formas de espiritualidad o de experiencias religiosas y en algunos casos a la conversión. En segundo lugar, tratar de reconstruir los rasgos que caracterizan al converso, en la búsqueda de sunuevaidentidad religiosa, al modificar su sistema de creencias y valores, para acercarnos en tercer lugar, a su percepción de la sociedad en la que viven. En este sentido, y aplicando una metodología cualitativa etnográfica, basada en el uso de la entrevista en profundidad y la observación participante, se ha utilizado como fuente principal de análisis los testimonios extraídos de las entrevistas realizadas a lo largo del trabajo de campo.

\section{EL FENÓMENO RELIGIOSO Y LOS ESTUDIOS SOBRE CON- VERSIONES}

Después de que se pronosticara en las décadas 70 y 80 del siglo XX, la decadencia, cuando no la desaparición, de la religión, motivada sobre todo por los procesos de secularización y globalización, en las décadas siguientes, este presagio no solo no se ha cumplido, sino que la religión ha dejado de ser interpretada como un fenómeno secundario destinado a la extinción y ha vuelto a ser eje central de interés científico. Pero, a pesar de que el fenómeno religioso sigue estando presente en los estudios académicos, fue a partir de la década de los 80 , cuando se comienza a mencionar la llamada recomposición religiosa, un concepto que permite valorar la complejidad que encierra el campo religioso, así como englobar las transformaciones individuales y sociales que se producen en las subjetividades religiosas. Ello nos permite tomar en consideración a las conversiones.

El fenómeno de la conversión estuvo considerado durante mucho tiempo y siguiendo a William James (1994) como algo inusual en las sociedades occidentales y se asociaba principalmente con los nuevos movimientos religiosos, fuertemente proselitistas que comenzaron su actividad en el siglo XIX. Este era el caso de la iglesia de Jesucristo de los Santos de los Últimos Días (mormones), fundada en 1830 o los Estudiantes bíblicos, antepasados de los Testigos de Jehová en 1878. Sin embargo, a partir de la década de los 80 , como venimos diciendo, además de aumentar el interés por el estudio de las distintas confesiones religiosas, se pusieron de moda los estudios sobre conversiones religiosas, sin duda alguna, porque también se pusieron de moda las conversiones. Así, en las sociedades occidentales cada vez han sido más frecuentes los cambios de una denominación protestante histórica a otra, conversiones del catolicismo al protestantismo o del catolicismo a alguna de las religiones orientales como el hinduismo o el budismo.

De esta forma, el fenómeno de las conversiones se ha convertido en un interesante objeto de estudio despertando el interés de los investigadores de las ciencias sociales 
y religiosas tales como la fenomenología de las religiones, la historia, la psicología, la antropología o la sociología. Quizás por lo paradójico que puede resultar este fenómeno en una sociedad cada vez más laica, se pueda explicar porque el estudioso se siente atraído por descubrir que hay detrás de ese proceso (Introvigne, 2010, p. 360). En este sentido, dentro de la literatura antropológica y sociológica sobre conversión, hay que destacar los trabajos de Simon Coleman (2003, 2004, 2014, 2017) en África y Asia, los estudios de Peter Van der Veer (1996 y 2009) sobre la globalización de las creencias y la conversión hoy en día, el trabajo de Nathaniel Roberts (2016) sobre la conversión al Cristianismo en el India o la gran cantidad de estudios sobre conversiones, que se han venido realizando en los últimos años, en el contexto de América Latina ${ }^{3}$. En este último caso se trata de investigaciones que intentan comprender las razones por las que los individuos se sienten motivados a abandonar la Iglesia Católica y adherirse a nuevos movimientos religiosos como el pentecostalismo (Sarrazín y Rincón, 2015), estudios sobre la conversión al pentecostalismo en Chile (Masías, 2010) o en México (Garma Navarro, 1999) o los trabajos sobre la conversión al islam como estrategia de cambio en Colombia (Sarrazín y Arando, 2017). Precisamente en este contexto hay que mencionar también las propuestas teóricas a cerca del propio concepto de conversión y donde encaja el interesante debate en torno a la utilidad del concepto de movilidad religiosa (Garma, 2018). Un concepto más amplio que el de conversión y que puede ayudar a incluir una mayor diversidad de experiencias religiosas ${ }^{4}$.

Para el caso que nos ocupa y refiriéndonos al contexto español hay que destacar los trabajos de Prat (1997) sobre la conversión a las sectas religiosas, de Vallverdú (1999) sobre la conversión a los Hare Krisna o los estudios de Manuela Cantón (2004) o Mena (2005) sobre la conversión de los gitanos españoles al cristianismo evangélico pentecostal, entre otros. No obstante, son todavía pocos los estudios que se han hecho sobre el atractivo que han venido despertando religiones orientales como el hinduismo o el budismo, un interés asociado al aumento de fieles españoles convertidos a estas religiones. Pensamos que esta fascinación por las religiones orientales, enmarcada dentro del llamado contexto de la privatización de la religión (Luckman, 1973) se relaciona con el interés que ha despertado la búsqueda individual de una religiosidad alternativa definida por la Sociología o la Antropología de la religión como espiritualidad (Heelas, 2008; Wood, 2009) en la que prima el subjetivismo religioso por encima de las instituciones religiosas tradicionales (Castilla, 2015), la comunidad de fe o los rituales colectivos (Cornejo, 2012). Es

3 Hay autores que mencionan que el interés por la conversión por parte de investigadores de Estados Unidos o el Reino Unido ha disminuido. En parte, porque los jóvenes de esos países no se sienten atraídos por los cambios en religiosidad y espiritualidad (Collins, 2010 o Garma, 2018)

4 Garma Navarro (2018) utiliza el término movilidad religiosa para explicar el cambio de credo no como un cambio drástico, sino como un proceso paulatino de búsqueda espiritual que no implica una experiencia única, sino que la transformación religiosa forma parte de una trayectoria de búsqueda prolongada en el tiempo. 
Revista de Humanidades, 38 (2019).p. 161-180. ISSN 1130-5029

en este contexto de subjetividades religiosas contemporáneas donde podemos entender el auge que ha experimentado el budismo en occidente y España no es una excepción. Un interés que se comprende en el marco de ciertos procesos como la desinstitucionalización de la religión, la individualización, la crítica cultural frente a una supuesta crisis de sentido en occidente, así como la necesidad de desarrollar una espiritualidad individual y cuidar la salud del cuerpo, la mente y el espíritu (Sarrazín, 2017). De esta forma, Jaume Vallverdú señala que la espiritualidad de hoy en día se caracteriza por "creencias y prácticas espirituales de raíz oriental" y nos recuerda que los movimientos religiosos con más demanda buscan una "satisfacción interior (...), un desarrollo religioso vinculado a un enriquecimiento de la conciencia" (Vallverdú, 2001). En este sentido, el budismo se adecúa perfectamente a este tipo de creencias y es una confesión que lejos de ser estigmatizada, goza de una gran aceptación social. En la mayoría de los casos se trata de personas españolas que realizan un acercamiento individual y que se interesan por la práctica y las ideas del budismo. La incorporación al grupo no les exige una relación previa con la cultura budista, y en muchos casos, no hay un abandono de la religión precedente, ya que algunos de los practicantes siguen considerándose también cristianos (Arroyo, 2013).

Dentro de los estudios sobre la conversión hay un buen número de ellos que se dedican a presentar modelos (Introvigne, 2010). Estos $\operatorname{modelos}^{5}$, propuestos desde las ciencias sociales y de la religión suelen centrase en tres dimensiones del fenómeno de la conversión. En primer lugar, se tiene en cuenta a la persona del converso y a los factores que pueden favorecer la conversión, partiendo de si es el individuo quien crea su nueva identidad religiosa o no, otorgando un papel activo o pasivo al sujeto ${ }^{6}$. También se tiene en cuenta al grupo (si es proselitista o no) y por último a la sociedad, como parte importante del proceso de conversión. Es evidente que lejos de ser considerada en segundo plano, la sociedad compleja y globalizada genera incertidumbres y tensiones y se hace más fácil que se produzca la crisis que desemboca en la conversión. Pero también esa misma sociedad globalizada facilita el encuentro de culturas. De esta forma, las expectativas que han existido siempre se ven incrementadas por la oferta religiosa que brinda la sociedad actual. Con la facilidad para viajar, la televisión, la radio o Internet, cualquier movimiento local puede adquirir una dimensión global, casi sin moverse del propio país. No puede sorprendernos

5 Introvigne (2010) nos presenta hasta cinco tipos de teorías de la conversión. Así, menciona los modelos fenomenológicos, modelos históricos, psicológicos, antropológicos y sociológicos.

6 Uno de los modelos más antiguos, que se centra en el papel activo del converso es el defendido por John Lofland y Rodney Stark. Un modelo que se remonta a 1965 y ha ejercido una enorme influencia en los estudios sobre la conversión. Este modelo prevé siete etapas por las que se supone debe pasar la persona que se convierte: Presencia de tensiones profundas y no pasajeras en la persona que se va a convertir, tendencia de la persona a buscar respuestas a sus problemas en un contexto religioso, transformación en un seeker que busca una verdad religiosa, encuentro, en un momento crucial de la vida, con un determinado grupo religioso, desarrollo de lazos afectivos con uno o más miembros del grupo encontrado, ruptura de las relaciones con las personas que se oponen al grupo e interacción intensa con los miembros del grupo (Lofland y Stark, 1965, pp. 862-875). 
que podamos encontrar comunidades de monjes tibetanos en las montañas de España o Italia, sin necesidad de marcharse al Tíbet (Introvigne, 2010, p. 366).

En los últimos años se ha empezado también a tener en cuenta el sistema de creencias y prácticas que son propuestas al converso o las que abandona para adquirir la nueva identidad religiosa. No siempre el sujeto es un agnóstico, una persona totalmente desinteresada por el fenómeno religioso. A menudo pertenece o ha sido educado en una religión que es mayoritaria en su país. Hablamos por ejemplo de los españoles que han sido educados en la religión católica y que la abandonan para integrarse en otra confesión.

A pesar de las diferencias existentes en las diversas interpretaciones a cerca de la conversión, sobre todo teniendo en cuenta la ciencia de acercamiento al fenómeno, hay una certeza que es compartida. La conversión no podía ser descrita como un fenómeno unitario y era necesario buscar una tipología que diferenciase varios tipos de conversión, entendida ésta como transformación del sujeto. De esta forma, Lofland y Skonovd (1983) llegaron a distinguir hasta seis modalidades principales de conversión según sea el tipo de motivación hacia ella: intelectual, mística, experimental, afectiva, "revivalista" y coercitiva. Para definir esta tipología se consideraron cinco dimensiones distintas: 1) el grado de presión social que implica la conversión; 2) la duración temporal de la experiencia; 3) el nivel de despertar emocional durante el proceso; 4) el contenido afectivo del mismo; 5) la secuencia creencia-participación. Cada una de las formas de conversión mencionadas puede variar a lo largo de estas cinco dimensiones. Por lo tanto, no se trata de modalidades o variantes necesariamente exclusivas e inmutables, sino que pueden darse de forma combinada y variable.

Por otro lado, el estudio de la conversión religiosa se ha venido abordando desde diferentes puntos de vista: la conversión individual o colectiva, activa o pasiva, repentina o paulatina, directa o indirecta. Renée de la Torre comenta que "durante muchos años prevaleció la tendencia a entender la conversión bajo el modelo "paulino", como la experiencia individual de una llamada de Dios, lo que traía aparejado un cambio de vida repentino, dramático y emocional, excluyendo el aspecto racional. En otros casos, principalmente desde una perspectiva más psicológica, se ha prestado atención al fenómeno de la conversión como consecuencia del lavado de cerebro, lo que conllevaba una transformación de la personalidad del sujeto, la ruptura de su vida anterior y la adopción de una nueva vida. Por otro lado, desde una interpretación cognitiva, se ha explicado la conversión como si el sujeto estuviera condicionado por unos marcos culturales que le predisponen a adoptar una nueva forma de interpretar el mundo (Torre, 1995, pp. 219-220).

En la mayoría de estos enfoques predomina una visión pasiva del sujeto de la conversión. Sin embargo, aunque entendemos que la conversión implica un cambio en la vida del sujeto, no la concebimos como una transformación cognitiva lineal y pasiva. Todo lo contrario. Precisamente, un punto fundamental de nuestro estudio es 


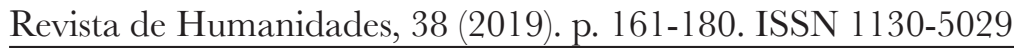

que entendemos la conversión como un proceso de cambio activo, multidimensional y progresivo. Se trataría entonces de un cambio entendido como una nueva forma de organizar la vida y que se hace manifiesto en una nueva forma de realizar las prácticas sociales. Precisamente, la bibliografía europea sobre itinerarios de conversión asume la progresividad como modo dominante en los procesos de conversión (Lenoir, 1999; Beck, 2009 y Sarrazin, 2017).

Berger y Luckman señalaron que la conversión religiosa es el arquetipo de la resocialización subjetiva de un individuo. En ella, el pasado se reinterpreta conforme con la realidad presente. El convertido centra su vida en la nueva realidad que eligió vivir y relata su experiencia de acuerdo con un vocabulario y un discurso adoptado (Berger y Luckman, 2006, p. 194). Se habla entonces de una construcción identitaria del sujeto, pues el cambio implica una nueva forma de actuar frente al mundo. Una transformación que trasciende el ámbito de lo religioso y se extiende a todas las esferas de la vida de la persona conversa. La forma de explicar su experiencia o el uso de un vocabulario nuevo, dan cuenta del cambio que ha producido la conversión (Berger y Luckman, 2006, p. 195).

Por su parte, la sociedad española ha cambiado mucho en materia religiosa y podemos mencionar varios aspectos que han ayudado a diversificar aun más las religiones presentes en el territorio. Por un lado, está el crecimiento de la inmigración internacional que se acrecienta a principios de este siglo. Inmigrantes que vienen de América Latina, de África, de Asia y del Este de Europa. Sin embargo, aunque algunos autores atribuyen gran parte de la pluralidad religiosa a la inmigración (Casanova, 2007), en el caso de España, y este sería un segundo aspecto, el incremento de fieles de confesiones no católicas no viene determinado solamente por la población inmigrada. Tenemos que prestar atención, también, al proceso de conversión de cierta población española como en el caso que nos ocupa, la conversión al budismo.

Otro de los puntos principales de esta investigación es que no es posible estudiar la conversión religiosa por sí misma, sino que, por su complejidad, es necesario considerar los contextos en los que ésta se produce, ámbitos culturales como la familia, el barrio, la comunidad o el país, contextos que a su vez se mantienen estrechamente vinculados a la historia personal del sujeto. En este sentido, hemos estudiado la conversión religiosa desde la cultura, y no sólo desde la conversión misma, prestando atención a los sujetos, pues ellos mismos "definen sus necesidades espirituales (...) y toman decisiones acerca del grado o la medida en que este propósito de satisfacerlas va a influenciar en sus vidas" (García, 1998).

\section{EL BUDISMO EN ESPAÑA: HISTORIA E INVESTIGACIONES}

El budismo es una de las religiones vivas más resistentes que cuenta con más de dos milenios de existencia. En la actualidad es la cuarta religión en número de 
seguidores tras el cristianismo, el islam y el hinduismo. Si bien es cierto que se suele pensar en el budismo como una religión asiática, en los últimos cuarenta años ha tenido un destacado crecimiento en Estados Unidos, Europa y Latinoamérica, protagonizando un proceso de globalización de prácticas y representaciones religiosas muy importante (Baumann, 2002 y Wallace, 2002).

En España podemos mencionar tres momentos en la relación con el budismo que irían desde los primeros contactos de misioneros con zonas asiáticas de religión budista hasta el reconocimiento del notorio arraigo en 2007, pasando por la aparición de las primeras comunidades budistas en suelo español a partir de 1977 (Diez de Velasco, 2007).

Asimismo, hace ya algunas décadas que se han ido estableciendo en España centros budistas de diversos orígenes enriqueciendo así el proceso de diversificación del campo religioso español. Hoy en día y según datos de la Federación Budista de España, se calcula que hay en torno a 300 centros budistas y unos 80.000 practicantes ${ }^{7}$. No obstante, a pesar del conocimiento de la existencia de centros budistas en nuestro país desde hace tiempo, ha sido un tema de investigación muy reciente como queda reflejado en el excelente trabajo de Diez de Velasco (2007). En este sentido, Diez de Velasco hace un recorrido bibliográfico remontándose a 1998 cuando Russell Webb realiza una revisión introductoria sobre la época del contacto del imperio español con zonas de mayoría budista en los siglos XVI y XVII, hasta llegar a nuestros días con los diversos estudios que analizan la implantación y el desarrollo del budismo en algunas comunidades autónomas españolas, resultado de investigaciones promovidas desde la Fundación Pluralismo y Convivencia (Madrid) enfocadas en general al estudio de las minorías religiosas en España (Diez de Velasco, 2008, 2012; Iglesias, 2007; Macías y Briones, 2010 y Macías, 2011, entre otros). Así, como trabajos más puntuales sobre alguna comunidad budista en particular, como los que desarrolla el equipo de Josep A. Rodríguez de la Universidad de Barcelona, sobre el grupo Sakya Tashi Ling, desde una perspectiva sociológica o el trabajo sobre los Soka Gakkai desde una perspectiva antropológica (Cornejo, 2012).

Como venimos diciendo, el interés por el estudio del budismo desde el punto de vista académico ha sido muy reciente, sin embargo, el interés por las prácticas budistas por parte de la población española se remonta bastante más atrás, como queda reflejado en los relatos de muchas de las personas interesadas por el budismo. Es importante destacar que como bien menciona Diez de Velasco, al no contar España con estrechas relaciones con el Asia budista, la fuerte inmigración que ha caracterizado a España, desde los años 90 hasta 2009, no ha tenido un componente destacado de budistas étnicos. Lo que hace que el budismo en España sea mayoritariamente una religión de conversos (Diez de Velasco, 2007).

7 En 1992 se crea la Federación budista de España y según el presidente de las comunidades budistas de España hay actualmente unos 80.000 fieles. 


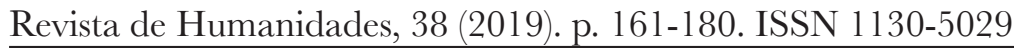

\section{EL BUDISMO EN GRANADA}

Desde sus orígenes en el siglo $\mathrm{V}$ a C. han surgido muchas maneras de entender esta religión tradicional, que cuenta con dos grandes caminos: Himayana o pequeño vehículo y Mahayana o gran vehículo. Dentro de esta última escuela encontramos al budismo tibetano en el que destacamos la figura del lama o guía espiritual. Precisamente, el surgimiento en el Tibet de varios linajes de lamas es lo que ha dado lugar al desarrollo de diferentes escuelas de pensamiento y prácticas budistas.

En Andalucía, el budismo y más concretamente el budismo tibetano, está presente desde 1980. Así, destacamos los centros de retiro como el de Osen Ling, seguidor del linaje Gelupa, en la localidad de Orgiva en la Alpujarra granadina. Un centro cuyo origen se remonta a los años 70 del siglo XX en la isla de Ibiza, con su conexión con el movimiento hippy y su forma de vida. Durante esa época, muchas personas se sintieron fascinadas por la India y su cultura, lo que les llevó a viajar a ese país y contactar con diversos lamas o maestros que posteriormente vinieron a la isla a impartir sus enseñanzas. Uno de estos lamas será el lama Yeshe que guiará la implantación del budismo en España. Posteriormente y ante el aumento de personas interesadas, surge el deseo de crear un centro en la península y se decide elegir las Alpujarras granadinas, por ser un enclave que podía recordar a los monasterios budistas. El centro se inauguró en 1980.

Por otra parte, en Granada capital, encontramos el centro de estudio de budismo tibetano, Nagarjuna, inaugurado en 1985 y en el que nos vamos a basar en nuestro trabajo. De esta forma, nos hemos centrado en reflexionar a cerca de cuales han sido las razones del indudable éxito del budismo en la ciudad de Granada a partir del trabajo de campo realizado y de las entrevistas con personas que acuden habitualmente al centro objeto de estudio. La metodología que hemos seguido en esta investigación se compone de 10 entrevistas semiestructuradas, a dos maestros y a 8 personas que hacen meditación. Asimismo, hemos llevado a cabo varias observaciones participantes en el centro Nagarjuna. Estas observaciones se llevaron a cabo, durante varias charlas sobre filosofía budista y varias sesiones de meditación.

Lo más interesante ha sido recoger las voces de los sujetos sociales que decidieron modificar su adscripción religiosa, muchos de los cuales habían recibido el bautismo católico y otros sacramentos. Por otro lado, hemos observado que, en la mayoría de las ocasiones, el acercamiento al budismo es una decisión de búsqueda individual. El fenómeno de la individualización como un síntoma de la modernidad ya ha sido estudiado por algunos autores como Baumann (2000), Guidens y Lash (2001), entre otros y en el caso del budismo es paradigmático de lo que decimos. Entre los entrevistados no se destaca el desarraigo, ni la exclusión social. Un elemento, éste último, que ha sido estudiado en otros grupos religiosos como por ejemplo los pentecostales (Folguer y Amenta, 2010; Martin, 2002). Sin embargo, había un tema que nos preocupaba y era el saber a quien considerar verdaderamente 
budista y por tanto converso, o simplemente una persona interesada por las prácticas. En este sentido, J. W. Coleman (2012) refiriéndose precisamente a los budistas conversos, pone de manifiesto que quizás, no tenga tanta importancia definir quién es o no budista, sino quien está involucrado en el budismo. Para estas personas lo importante en el cambio de creencia era el trayecto en si y la búsqueda individual de experiencias religiosas o espirituales y no tanto la meta. Precisamente el llamado modelo individualista se desarrolla a partir de la exploración de uno mismo. Estas nuevas espiritualidades, entre las que podemos incluir al budismo, presentan un carácter abierto y holístico que favorece el cultivo de lo personal y la integración de diferentes fuentes de experiencia y de conocimiento (Cornejo, 2012, p. 330). Está claro que en las sociedades occidentales tendemos a encasillar a una persona en una u otra religión, sin considerar que esa misma persona pueda elegir simultanear dos religiones ${ }^{8}$. Así, entendemos que la religión es un instrumento más, que elige el individuo, para ir construyendo su identidad, entendiendo ésta como múltiple.

\subsection{La meditación es el comienzo}

El centro Nagarjuna se encuentra en un cuarto piso de un edificio de apartamentos. Se trata de un piso remodelado para las prácticas que allí se llevan a cabo. Una pequeña recepción, decorada con imágenes de distintos lamas, entre los cuales destaca el Dalai Lama, nos da la bienvenida. Las paredes son blancas pero los trajes rojo y naranja de las fotografías logran crear una atmósfera de bienestar. Además, abundan diferentes figuras de Buda. El día que acudimos al centro por primera vez había meditación. Antes de comenzar con la sesión de meditación, las personas presentes, cuatro mujeres y dos hombres, además de la persona que va a dirigir la meditación, deambulaban por la sala o se detenían a leer algunos de los libros de las estanterías. Lo primero que se hace es dar la bienvenida a quienes asisten por primera vez. Se les explica en qué consiste el centro, se les invita a descalzarse nada más entrar y a liberarse de la rutina y de la esclavitud de la vida cotidiana para dedicarse un rato a sí mismo. A continuación, se anuncia el comienzo de la meditación $\mathrm{y}$ todos se sientan en el suelo, sobre cojines, con los ojos cerrados. La primera parte de la sesión duró unos 20 minutos, seguidos de un descanso de cinco y una segunda sesión de 30 minutos. Durante todo el tiempo el guía recordaba que no debemos deshacernos de los pensamientos que iban llegando a nuestra mente. Solamente había que dejarlos allí y verlos pasar. Ayudándonos además de la respiración. Finalmente llegó el sonido de una especie de "bol de madera" (cuenco tibetano) que sería la señal para abrir los ojos. Al terminar la meditación aproveché la ocasión que se me brindaba para poder conversar con las personas que allí se encontraban. En este caso todas ellas, las cuatro mujeres y los dos hombres, eran españolas.

8 Hay autores que hablan de una especie de "bricolaje" al tratar de explicar como los individuos en su búsqueda espiritual, combinan elementos procedentes de contextos diferentes (Beck, 2009). 


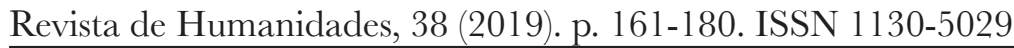

El budismo ve a la vida como un proceso en constante cambio, otorgando un importante papel al individuo y a la tarea personal de superación de las dificultades mediante una serie de enseñanzas prácticas. En este sentido, se parte de la idea de que la mente es el motor de ese cambio, con lo cual hay que buscar la forma de trabajar con ella. Una de las prácticas budistas más importantes es la meditación. Se trata de una serie de técnicas que ayudan a desarrollar estados mentales positivos que se caracterizan por buscar la concentración, la tranquilidad o incluso la felicidad. Un medio para que uno mismo se transforme tratando de soportar las dificultades, comprendiéndose a si mismo y a los demás. En este sentido, me interesaban los sujetos mismos, sus experiencias vividas y el sentido que otorgaban a sus acciones. De esta forma, me pareció importante conocer de primera mano la idea que tenían de la meditación las personas que habían participado en la misma. Así como los motivos que les llevaron a interesarse por el budismo.

"Más que una religión el budismo es un conjunto de ideas que ayudan al individuo a liberarse de la opresión que causa el odio, la envidia, la ignorancia. Todo eso hace que la vida se desaproveche (...). Lo que más me ha gustado siempre del budismo es la práctica de la meditación. Para mi ha sido siempre muy importante porque me ha ayudado a afrontar los problemas por mí misma" (mujer que práctica la meditación budista, 54 años).

"En un principio no me gustaba eso de la meditación. Me producía risa y me parecía una pérdida de tiempo. Pero tuve algunos problemas de ansiedad que luego desembocaron en problemas más graves. Ello me llevo a consultarlo todo. Un día me atreví a venir al centro. Fue una decisión personal, no lo comenté con nadie porque me daba un poco de vergüenza. Todos mis familiares y amigos son muy católicos y me parecía que me iban a decir que estaba loca. Allí descubrí que mis problemas eran mentales más que físicos. La meditación me da una paz interior que no había sentido antes. Ahora soy capaz de hablarlo y no me importa tanto el que dirán (mujer que práctica la meditación budista, 45 años).

Uno de los primeros aspectos que tenemos que mencionar es que el porcentaje de conversos budistas en la ciudad de Granada no es alto, sin embargo, si hemos observado un elevado número de practicantes de meditación budista. Lo que nos lleva a pensar que la gran mayoría de los conversos comenzaron interesándose por las prácticas antes que por la doctrina9 ${ }^{9}$. Asimismo, si bien las razones para llegar al budismo son diferentes, en la mayoría se menciona curiosidad, a la vez que una insatisfacción que les lleva a buscar respuestas.

9 Podríamos añadir que esta idea se puede vincular con los procesos asociados a los itinerarios de tipo New Age que surgieron en los años 80 y en los que se destaca el discurso sobre la necesidad de desarrollar la espiritualidad individual y la salud del cuerpo, la mente y el espíritu a través de terapias orientales para ayudarnos a alcanzar el bienestar integral (Sarrazin, 2017, p. 70). 
"Me encontraba en un momento angustioso, no encontraba una salida. Lo curioso es que tenía trabajo y una familia, pero cada día estaba más hundida. Nada me satisfacía y se resintió la relación con mi pareja e hijos. Un día por curiosidad me encontré un papel en mi buzón donde se anunciaban unas charlas de filosofía oriental y así fue como vine a este centro. En ese momento cambió mi vida, comenzó un nuevo camino y comencé a vivir de otra manera" (mujer que practica la meditación budista 45 años).

En otros casos, tuvieron conocimiento del centro y del grupo a través de otra persona. En este sentido, es interesante mencionar que aunque la decisión es individual, destacan en su relato la importancia de personajes secundarios, sean parientes o amigos, que influyen en el éxito de la futura conversión.

"Lo conocí -se refiere al Centro- por una amiga que hacía meditación. Yo fui con ella

y me gustó. Siempre había sentido curiosidad por la filosofía oriental. Había leído muchos libros sobre meditación, pero no sabía mucho antes de ir a las charlas. Tengo que agradecer a esta amiga que me hablara de ello" (mujer que práctica la meditación budista, 54 años).

También es cierto, según nos contaron, que la práctica religiosa es diferente dependiendo de las diversas escuelas del budismo. Para el caso del budismo tibetano la meditación es fundamental y requiere de constancia y esfuerzo por parte de quienes lo practican. Decíamos anteriormente que el acercamiento al budismo es una decisión individual y se elige por encima de las muchas opciones que la sociedad te ofrece. En este sentido, el sujeto está más comprometido en ser él mismo quien dirija su propia vida y construya su propio yo. Como nos decía una informante:

"En el budismo no te obligan a que adoptes la religión, lo que si hacen es poner sus enseñanzas a tu disposición. Cada uno busca su camino. Yo me sentí libre en todo momento. Elegí por mi misma" (mujer que practica la meditación budista, 45 años).

Es interesante destacar como las palabras "cada uno busca su camino", "elegí por misma", revela esa individualización que mencionábamos más arriba, como elemento destacado en las nuevas formas de creer que se dan en el mundo contemporáneo.

\subsection{Tolerancia y adaptación}

Por otro lado, otro aspecto que destacan los informantes es la tolerancia de los budistas respecto a otras religiones y corrientes de pensamiento, lo que le otorga un alto grado de aceptación por parte de la población. Asimismo, también se le otorga al budismo una gran capacidad de adaptación, adecuando su mensaje a diferentes lugares, contextos u expectativas personales. En este sentido, es interesante resaltar como las técnicas de meditación se adaptan a las necesidades del mundo moderno, caracterizado por grandes dosis de estrés. Por tanto, es evidente que las conversiones 


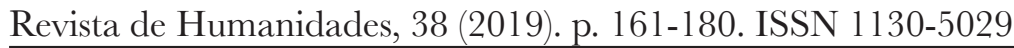

al budismo corresponden a una necesidad de regeneración personal. La persona busca el bienestar y la paz, más que la verdad ${ }^{10}$.

"Pienso que (el budismo) tiene éxito porque es una religión que se considera pacífica, muy tolerante e inofensiva. Solo te enseña como conseguir la paz interior mediante técnicas de meditación adaptadas a las necesidades de hoy en día (mujer budista, 60 años).

"No he sentido rechazo, porque el budismo no suele provocar rechazo" (mujer budista, 60 años).

"No me enfado tanto e intento mantener unas relaciones personales más pacíficas" (mujer que practica la meditación budista, 54 años).

Asimismo, algunos de los entrevistados destacan también la importancia de tener un centro de meditación. Insisten en la necesidad de disponer de un lugar, donde el que lo desee, pueda estudiar las enseñanzas budistas. De esta forma, hacen referencia a algunas de las charlas a las que han asistido en el centro. Estas conversaciones nos ponen de manifiesto que tanto el contenido que se imparte en las charlas, como la forma de hacerlo, es una historia adaptada al pensamiento occidental. Se habla del amor, del sufrimiento, de la compasión por los otros. Pero todos se encuentran cómodos por sentirse reconocidos en los comentarios de la persona que dirige las charlas.

"Por eso necesitamos un centro de meditación [hablando de las charlas que se imparten]. Una de las cosas que aprendemos es que la esencia de las enseñanzas es la compasión hacia todos los seres. Cuando las personas llegan a un centro de darma dejarán de dañar a los seres" (mujer que hace meditación budista, 55 años).

"Es la sensación de paz que se desprende en el centro cuando hacemos meditación lo que me hace sentir bien conmigo misma. La meditación te hace bien. Si no estás bien contigo, no puedes estar bien con los demás" (mujer budista, 60 años).

\subsection{Construyendo identidad al "irse convirtiendo".}

Berger y Luckman (2006, p. 194) hablaban de como el convertido centra su vida en el presente, y relata su experiencia de acuerdo con un vocabulario y un discurso aprendido dentro del grupo. La forma de dar testimonio, el uso de determinadas palabras que no forman parte del vocabulario cotidiano, todo da cuenta del cambio, de la conversión.

10 A propósito de las etapas en el proceso de conversión, hay que destacar el estudio de Thierry Mathé (2005) sobre las conversiones al budismo en Francia, quien sostiene que estas conversiones obedecen a una necesidad de "regeneración". 
Nuestra experiencia con personas budistas nos ha llevado a poner de manifiesto que, si bien estas personas conversas hablan de cambio, en su discurso no se menciona la palabra ruptura con lo anterior. Tenemos por tanto que hablar de la posibilidad de una continuidad. No se trataría tanto de romper con todo lo anterior sino de utilizar las enseñanzas budistas como estrategia de respuesta frente a un mundo en cambio. La transformación religiosa no implica una experiencia única, sino que el cambio forma parte de una trayectoria de búsqueda prolongada. Como mencionábamos más arriba, lo importante para ellos es el trayecto en sí mismo, antes que la llegada a la meta.

Asimismo, la mayoría se reconoce como estudiosos de las enseñanzas budistas, pues la conversión es algo más profundo. Convertirse en budista implica comprometerse con los ideales centrales del budismo. Estos son el Buda, como modelo, el Dharma, las enseñanzas y prácticas del budismo; y la Sangha, la comunidad de personas que también están siguiendo el camino y que te aportan amistad, estímulo, inspiración y guía. Aceptar estas tres ideas indica aceptar el budismo como seña de identidad, algo que no es inmediato.

Por otra parte, más allá de que consideremos la conversión al budismo como repentina o gradual, activa o pasiva, en nuestro caso, quizás lo más conveniente seria hablar, como ya lo hiciera William James hace más de un siglo, de "irse convirtiendo" al budismo. De hecho, los informantes indican la importancia de darse un tiempo para considerarse budistas.

"Llegar a ser budista es todo un proceso espiritual interno que va desde el interior al exterior a través de la reflexión y la meditación. Muchas personas se centran en las prácticas de la meditación o la filosofía de vida del budismo, como el no hacer daño o el vegetarianismo, porque mejora sus vidas, pero luego no se consideran budistas. En mi caso, yo soy un estudiante del budismo. Ser budista implica conversión y para ello uno debe estar listo (hombre que práctica la meditación budista, 55 años).

"Ser budista es más que meditar. La meditación nos ayuda, pero ser budista es ser capaz de aplicar lo que trabajas en la meditación a tu día a día y eso se consigue con la práctica. No llega de repente" (hombre que práctica la meditación budista, 60 años).

\section{REFLEXIONES FINALES}

El crecimiento del budismo en España ha sido evidenciado a través del interés que vienen demostrando personas españolas interesadas por esta religión oriental. Debemos reconocer que un estudio sobre el conjunto de causas que influyen en el fenómeno de la conversión y concretamente en la conversión al budismo, va más allá de un análisis etnográfico y de los relatos presentados en este artículo. No pretendemos dar respuestas categóricas y definitivas a porqué las personas se convierten al budismo porque en muchos casos estas mismas personas no están exentas de conflictos, dudas y resistencias frente a la sociedad. Precisamente esas 


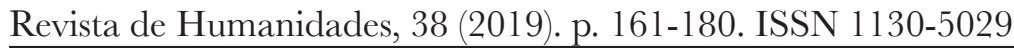

dudas e inquietudes que están detrás de las decisiones de esas personas son las que nos han interesado realmente y lo que nos lleva a seguir investigando. No obstante, podemos concluir con algunos apuntes finales a modo de reflexión.

Siguiendo la clasificación que hicieran Lofland y Skonovd (1983) la conversión al budismo se podía considerar afectiva, intelectual y experiencial. No hay una presión ejercida por el grupo pues las personas que se acercan a esta religión lo hacen voluntariamente. En la mayoría de los casos han sentido curiosidad por las enseñanzas budistas lo que les ha llevado a leer libros sobre la meditación o el budismo. Por tanto, hay que destacar el papel activo que se le otorga al individuo.

El acercamiento a las personas con las que hemos contactado nos hace pensar que el budismo es una religión aceptada. Hay una percepción muy positiva hacia el budismo y no hay estigma social. Las motivaciones para acercarse al budismo son varias, pero principalmente es la insatisfacción lo que les hace buscar cosas nuevas y buscan respuestas en la religión. En este sentido, la conversión modifica la percepción de la identidad personal y se puede decir que marca un hito en la vida de las personas. La mayoría dicen haber llegado a la meditación por amigos que le dan cuenta de su experiencia. De esta forma, las personas que han llegado al budismo lo han hecho interesándose en primer lugar por las prácticas, principalmente por la meditación y luego por la enseñanza y la doctrina. Todos mencionan que la meditación les ha cambiado para mejorar. Les hace sentirse bien y ser mejores personas porque ven mejor a los demás. El individuo se siente más íntegro, menos en lucha consigo mismo. Lo que nos lleva a concluir que la persona busca el bienestar más que la verdad. Aunque también admiten la oportunidad de reconstruir y dar sentido a sus vidas.

Añadiríamos también que la conversión entraña una construcción identitaria porque como indican Berger y Luckman (2006), el cambio implica una nueva forma de actuar frente al mundo. No obstante, este cambio puede ser gradual y no siempre se produce de forma repentina, ni a través de un ritual de paso. Los informantes insistían en que había que ir despacio, "hay que darse un tiempo para ser considerados como budistas", hay que ir convirtiéndose en budistas poco a poco. Entendemos por tanto la conversión al budismo como un proceso a largo plazo.

\section{BIBLIOGRAFÍA}

Arroyo Moliner, L. (2012). El budismo en España: un estudio sociológico pionero. Barcelona: Universidad de Barcelona.

Arroyo Moliner, L. (2013). Espiritualidad, razón y discordancias: el budismo ahora y aqui (Tesis doctoral). Barcelona: Universidad de Barcelona.

Baumann, M. (2002). Buddhism in Europe: Past, Present, Prospects. En Prebish, C. S. and Baumann, M. (eds.). Westward Dharma: Buddhism beyond Asia. Berkeley and Los Angeles: University of California Press, pp. 85-105. 
La conversión religiosa como instrumento de búsqueda... - C. Castilla-Vázquez

Beck, U. (2009). El dios personal: la individualización de la religión y el espíritu del cosmopolitismo. Barcelona: Paidós.

Berger, P. y Luckman, T. (2006). La construcción social de la realidad. Buenos Aires: Amorrortu.

Briones, R. (dir.) (2010). ¿Y tú de quién eres?: minorías religiosas en Andalucía. Barcelona: Icaria, pp. 363-405.

Cantón Delgado, M. (1998). Bautizados en fuego: protestantes, discursos de conversión y política en Guatemala (1989-1993). La Antigua Guatemala: CIRMA y Plumsock Mesoamerican Studies.

Cantón Delgado, M. et al. (2004). Gitanos pentecostales: una mirada antropológica a la iglesia filadelfia en Andalucía. Sevilla: Signatura.

Cantón Delgado, M.; Prat, J. y Vallverdú, J. (coords.) (1999). Nuevos movimientos religiosos, iglesias y 'sectas'. Santiago de Compostela: Asociacion Galega de Antropoloxia Social y Cultural.

Casanova, J. (2007). Reconsiderar la secularización: una perspectiva mundial. Revista Académica de Relaciones Internacionales, n. 7, pp. 1-20. Disponible en: http://hdl. handle.net/10486/678436

Castilla-Vázquez, C. (2015). Del desinterés al entusiasmo. El fenómeno religioso en la investigación etnográfica española. Gazeta de Antropología, n. 31 (2), art. 1. Disponible en: http://www.gazeta-antropologia.es/wp-content/uploads/GA-31-201 CarmenCastilla.pdf

Coleman, J. W. (2012). Who Is a Buddhist?. Buddhist-Christian Studies, 32, 33-37. Disponible en: http://www.jstor.org/stable/23274465

Coleman, S. (2003). Continuous conversión? The rhetoric, practice and rhetorical practice of charismatic protestant conversión. In Buckser, Andrew and Glazier, Stephen D. (eds.). The Anthropology of religious conversión. Oxford: Rowman and Littlefield, pp. 15-28.

Coleman, S. (2004). The globalisation of charismatic christianity. Cambridge: Cambridge University Press.

Coleman, S. (2014). Pilgrimage as Trope for an Anthropology of Christianity. Current Anthropology, v. 55, Supplement 10, pp. 281-291. doi: https://doi. org/10.1086/677766

Coleman, S. (2017). Bringing conversión down to earth. Jounal of religious and political practice, n. 3, issue 1-2, pp. 80-83. doi: https://doi.org/10.1080/20566093.2017.1 292172

Cornejo, M. (2012). Religión y espiritualidad, ¿dos modelos enfrentados?: trayectorias poscatólicas entre budistas Soka Gakkai. Revista Internacional de Sociología, 70(2), pp. 327-346. doi: http://dx.doi.org/10.3989/ris.2010.09.08

Díez de Velasco, F. (2002). Introducción a la Historia de las Religiones. Madrid: Trotta (3.a ed., 1.a ed. 1995; 2.a ed. 1998).

Díez de Velasco, F. (2007). Planteamientos metodológicos preliminares para el estudio del budismo en Canarias: crónica de un experimento de historia oral. En Díez de 
Revista de Humanidades, 38 (2019).p. 161-180. ISSN 1130-5029

Velasco, F. y Alberto Galván, J. (eds.). Las religiones minoritarias en Canarias, hoy: perspectivas metodológicas. Santa Cruz de Tenerife: Idea, pp. 367-402.

Díez de Velasco, F. (2008). La pluralidad de los budismos en Canarias. En Díez de Velasco, F. (ed.). Religiones entre continentes: minorías religiosas en Canarias. Barcelona: Icaria, pp. 265-284.

Díez de Velasco, F. (2012). Religiones en España: historia y presente. Madrid: Akal, pp. 278-293.

Fernández-Coronado, A. (2009). Notorio arraigo de la Federación de Comunidades Budistas de España (Consideraciones jurídicas sobre la evolución del concepto de notorio arraigo). Bandue: revista de la Sociedad Española de Ciencias de las Religiones, n. 3, 137-154.

Garma Navarro, C. (2018). Conversión y movilidad religiosa: propuesta de análisis. Cultura y representaciones sociales, año 12, n. 24, pp. 97-130. doi: https://doi. org/10.28965/2018-024-04

Heelas, P. (2003). The New Age Movement. The Celebration of the Self and the Sacralization of Modernity. Oxford: Blackwell.

Heelas, P.; Woodhead, L. et al. (2008). The Spiritual Revolution. Why Religion is Giving Way to Spirituality. Oxford: Balckwell.

Hervieu-Léger, D. (1996). Por una sociología de las nuevas formas de religiosidad: algunas cuestiones teóricas previas. En Giménez, Gilberto (comp.). Identidades religiosas y sociales en México. México: Instituto de Investigaciones Sociales/ UNAM.

Hervieu-Léger, D. (2004). El peregrino y el convertido, la religión en movimiento. México: Ediciones del Helénico.

Introvigne, M. (2010). El hecho de la conversión religiosa. Scripta Theologica, v. 42, pp. 359-383. Disponible en: http://hdl.handle.net/10171/11679

James, W. (1994). Las variedades de la experiencia religiosa. Barcelona: Península.

Lenoir, F. (1999). Le Bouddhisme en France. Paris: Fayard.

Lofland, J. y Stark, R. (1965). Becoming a World-Saver: A theory of conversión to a deviant perspective. American Sociological Review, v. 30, pp. 862:875.

Lofland, J. y Sknonoud, N. (1983). Patterns of conversión. En Barker, E. (dir.). Of Gods and Men. New Religious Movements in the West. Macon (Georgia): Mercer University Press, pp. 1-24.

Luckmann, T. (1973). La religión invisible: el problema de la religión en la sociedad moderna. Salamanca: Sígueme.

Macías, C. (2011). Practicantes del dharma en Andalucía. Revista de Humanidades, n. 18, pp. 11-36. doi: https://doi.org/10.5944/rdh.18.2011.12877

Macías, C. y Briones, R. (2010). Budismos en Andalucía. En Briones, R. (dir.) ¿Y tú de quién eres?: minorías religiosas en Andalucia. Barcelona: Icaria, pp. 363-405.

Mathé, T. (2005). Le Bouddhisme des Français. Contibution à une sociologie de la conversión. Paris: L’Harmattan. 
La conversión religiosa como instrumento de búsqueda... - C. Castilla-Vázquez

Mena Cabezas, I. (2005). Las huellas de la experiencia. Creencia, conversión y reflexividad. Gazeta de Antropología, n. 21, art. 27. Disponible en: https://www. ugr.es/ pwlac/G21_27Ignacio_Mena_Cabezas.html

Moreno Baptista, C. y Castellanos, J. M. (2011). Editorial. Virajes: Revista de Antropología y Sociología, v. 14, n. 2, pp. 7-11.

Pinto de Cea Naharro, M. M. (2009). Budismo y cristianismo en diálogo. Madrid: Dykinson.

Prat, J. (1997). El estigma del extraño: un ensayo antropológico sobre sectas religiosas. Barcelona: Ariel.

Rambo, L. (1996). Psicosociología de la conversión religiosa. Barcelona: Herder.

Roberts, N. (2016). To be cared for: the power of conversión and foreignness of belonging in an indiam slum. Oakland: University of California Press.

Sarrazin, J. P. (2017). Budismo universal, budismo individual. Análisis del interés por la espritualidad oriental en occidente. Escritos, v. 25, n. 54, pp. 59-81. doi: http:// dx.doi.org/10.18566/escr.v25n54.a04

Torre, R. de la (1995). Los hijos de la luz: discurso, identidad y poder en la Luz del Mundo. Guadalajara (México): Universidad de Guadalajara, Departamento de Estudios en Comunicación Social, p. 219.

Vallverdú, J. (1999). Conversión, compromiso y construcción de identidad en el movimiento Hare Krisna. Alteridades, 9 (18), pp. 57-70. Disponible en: https:// alteridades.izt.uam.mx/index.php/Alte/article/view/441

Vallverdú, J. (2001). Mercado religioso y movimientos carismáticos. Gazeta de Antropologia, n. 17, art. 22. Disponible en: http://www.ugr.es/pwlac/G17_22Jaume_ Vallverdu.html

Van der Verr, P. (ed.) (1996). Conversion to Modernities. The Globalization of Christianity (Zones of Religion). New York and London: Routledge.

Van der Veer, P. (2009). Spirituality in Modern Society. Social Research: An International Quarterly, 76(4), pp. 1097-1120.

Wallace, A. (2002). The Spectrum of Buddhist Practice in the West. En Prebish, Ch. y M. Baumann. Westward Dharma: Buddhism Beyond Asia. California: University of California Press, pp. 34-50.

Woodhead, L. and Heelas, P. (2000). Religion in Modern Times: an Interpretative Anthology. Oxford: Blackwell. 